\title{
Oral Surgeon
}

National Cancer Institute

\section{Source}

National Cancer Institute. Oral Surgeon. NCI Thesaurus. Code C17825.

A surgeon with advanced training in treating diseases and disorders of the oral cavity. 